\title{
The Effects of Adding Lysin Essential Amino Acid to Commercial Feed on Fatty Acid Contents of Pangasius Fish
}

\author{
Wahyu Nopita ${ }^{1}$, Mirni Lamid ${ }^{2} *$ and Agustono ${ }^{1}$ \\ ${ }^{1}$ Department of Fish Health Management and Aquaculture, Faculty of Fisheries and Marine, Universitas Airlangga, Surabaya, East Java, Indonesia \\ ${ }^{2}$ Department of Animal Husbandry, Faculty of Veterinary Medicine, Universitas Airlangga, Surabaya, East Java, Indonesia \\ *Corresponding author's Email: mirnylamid@yahoo.com ; (DORCiD: 0000-0001-6539-4571
}

\begin{abstract}
Pangasius is a medium to very large freshwater shark catfish primarily used for consumption with high economic value. The content of pangasius fatty acids is higher than in marine fish, since marine fish have a lower saturated fatty acid composition than freshwater fish. The present research aimed to determine the effects of adding lysine essential amino acid to commercial feeds on the saturated and unsaturated fatty acids contents of pangasius fish. In the present research, an experimental method with completely randomized design was used. The treatment was done by adding lysine with different doses including P0 (0\%), P1 (1.2\%), P2 (2.2\%), and P3 (3.2\%). Each treatment was repeated five times. The main parameters studied were the content of saturated and unsaturated fatty acids in pangasius fish meat. The observed parameter was water quality. The present results indicated the use of lysine in commercial feed caused significant differences in the content of saturated fatty acids, Monounsaturated Fatty Acids (MUFA) and Polyunsaturated Fatty Acids (PUFA) in pangasius meat; a decrease in the saturated fatty acids content was found in P3 with 3.2\% (3.5882 mg/dl). In P2, an increase in the MUFA content of $2.2 \%$ (5.9630 mg/dl) was found. An increase in the PUFA content was found in P3 treatment with 3.2\% Lysin (23.1082 mg/dl). P1, P2 and P3 indicated lower results than control treatments $\left(\mathrm{P}_{0}\right)$. The use of lysine in commercial feed indicated significant differences in the content of saturated fatty acids, MUFA and PUFA in pangasius.
\end{abstract}

Key words: Lysine essential amino acid, Saturated fatty acids, Unsaturated fatty acids.

\section{INTRODUCTION}

Pangasius is a type of freshwater consumption fish that has high economic value. However, the fatty acids content in fresh pangasius meat is high, which could reach up to 61.64\% (Prananingtyas and Rahardja, 2019). The composition of fatty acids in pangasius in freshwater differed from the fish that live in marine waters. Marine fish had a lower composition of Saturated Fatty Acids (SFA), which are high in Polyunsaturated Fatty Acids (PUFA), which has been proven to be good for consumption as Unsaturated Fatty Acids (UFA) in marine fish are good for health (Weya et al., 2017).

Fatty acids are divided into SFA and UFA. Saturated fatty acids have a higher melting point than UFA and are the basis for determining the physical properties of fat (Bell et al., 2017). The excessively high-fat content led to an accumulation of fat in the body and disrupted the body's metabolic processes. Fatty acids that contain two or more double bonds are called PUFA (Sokoła-Wysoczańska et al., 2018).

One of the factors affecting pangasius fatty acids is their feed. The fat in their feed affected the composition of fatty acids in the body of pangasius. Fish feed was made of a material that can be eaten, digested, and absorbed either in whole or in part and would not cause poisoning or harm the health of the fish that consume it. The feed quality was considered to be poor if the content of essential amino acid was low (Van Doan et al., 2014; Bayati Zadeh et al., 2017; Mahmud et al., 2020).

Pangasius farmers were used commercial feed containing a variety of nutrients. However, the fatty acid content of pangasius still tends to be high. Additional feed supplement must be given to stimulate growth or increase productivity, reduce fat content and increase production efficiency. Feed supplement is a mixture of ingredients to improve the nutrients balance, which could be given without mixing with other foods to form a complete food. The use of feed supplements could increase the efficiency of food digestion so that fish farm production could be increased (Jana et al., 2014).

One of the feed supplements that could be added to the feed is lysine. Lysine is one of the essential amino acids for fish. Lysine plays a role in the formation of carnitine, which acts as a growth booster (Fitriani et al., 2019). The impact of the lysine, which is added to pangasius in commercial feed given to, is that it could stimulate the metabolic process of 
fatty acids in the body of pangasius (Liu et al., 2011). The current study aimed to determine the effects of adding lysine to commercial feed to reduce the content of SFA and increase the UFA contents of pangasius meat.

\section{MATERIALS AND METHODS}

\section{Ethical approval}

Present experiment was conducted on fish farm of the Universitas Airlangga of Indonesia. The research process included animals as a subject that was consistent with the ethical research principle based on the regulation of Research Ethic Committee. The present study implemented the basic principles of ethics of respect, benefit, non-deficiency, and justice.

\section{Experimental design}

The present study used a four-treatment experimental method to compare the effects of commercial feed without lysine with commercial feed with lysine. The addition of lysine was given a different dose for each treatment. Treatments $\mathrm{P}_{0}, \mathrm{P}_{1}, \mathrm{P}_{2}$, and $\mathrm{P}_{3}$ indicated the effects of different dosage of lysin on saturated and unsaturated fatty acid content of pangasius (Kim et al., 2018). The treatments used in the present study were the addition of lysine to commercial feeds at varying doses and were monitored and controlled. Treatment and repetition consisted of treatment $\mathrm{P}_{0}(100 \%)$ and commercial feed. The experimental design used was Completely Randomized Design (CRD) with four treatments and five replications. The experiments were performed with a simple random sample (Laake et al., 2013).

Pangasius fish were hybrid pasupati pangasius larvae that were kept in a fiber tube measuring $57 \mathrm{~cm} \times 36 \mathrm{~cm} \times 29$ $\mathrm{cm}$ for 42 days. The results indicated that the initial stocking density was 20 heads/L, 40 heads/L, 60 heads/L, 80 heads/L and 100 heads/L, there were differences in survival, in absolute length growth and in absolute weight growth. The best initial stocking density is 40 heads/ $\mathrm{L}$ with a survival rate of $66.14 \%$, an absolute increase in length of $5.03 \mathrm{~cm}$ and an absolute weight increase of 2.05 grams. The feed measure was five percent of biomass of pangasius by weighing the entire fish population. The feed was given twice every seven days, in the morning at 08:00 and in the evening at 16:00 (Jana et al., 2014). The frequency of feeding was determined by the species and size of the fish (Yoo and Lee, 2016), as well as by the factors that affect the appetite of fish. Basically, these three factors were closely related. The smaller the fish, the more often it is fed (Jana et al., 2014).

Freshwater with a volume of 22.5 liters per aquarium and 20 aquariums with a size of 30 centimeter $(\mathrm{cm}) \times 30 \mathrm{~cm}$ $\times 40 \mathrm{~cm}$, and a water height of $25 \mathrm{~cm}$ were used as Maintenance media. The fish used in the present study was pangasius with a size of seven to nine $\mathrm{cm}$, an average weight of $6.48 \pm 0.68 \mathrm{~g} / \mathrm{head}$ and a stocking density of up to one fish $/ 1$. The feed used in the present research is commercial pellet feed, which is Hi-Pro-Vite 781. The first step was to grind the pellet so that it became smaller. The ground pellet feed was then sieved to obtain the desired particles. The next+++ step was to weight the ground pellet. The Analysis of Variance (ANOVA) was applied to the data analysis. If a difference was found, the analysis was followed by Duncan's Multiple Range Test at a real level of 5\% to determine whether the addition of lysine in commercial feed to fish has an effect (Adi and Nugroh, 2020).

\section{RESULTS AND DISCUSSION}

Based on Duncan's multiple range test, it can be seen that P0 ( $p<0.05)$ was not significantly different in P1, P2, and P3 treatments. P1 was not significantly different in P0 and P2 but was significantly different in P3. The P3 treatment was not significantly different compared to P0 but was significantly different from P1 and P2 treatments. In summary, the lowest SFA content in pangasius meat was found in P3 treatment (3.5882\%), while the highest SFA content was $5.6868 \%$ as found in the P1 treatment with the addition of essential amino acids by $1.2 \%$ (Table 1).

Based on Duncan's Multiple Range Test, P0 ( $\mathrm{p}<0.05$ ) was not significantly different from treatments P1, P2, and $\mathrm{P} 3$. The treatment of $\mathrm{P} 1$ was not significantly different from $\mathrm{P} 2$, and P3. The lowest SFA content in pangasius meat was $3.5882 \%$ and could be found in the P3 treatment with the addition of lysine of $3.2 \%$, while the highest SFA content was $5.6868 \%$ in the P1 treatment with the addition of $1.2 \%$ essential amino acids (Table 2).

Duncan's multiple range test results indicated that P3 was significantly different $(\mathrm{p}<0.01)$ between P0, P1, and P2 treatments, while the P0 treatment was not significantly different from the P1 and P2 treatments. The lowest content of PUFA treatment in pangasius meat was found in the P0 treatment $(15.7392 \%)$ without essential lysine, while the PUFA content was $23.1082 \%$ in the P3 treatment with the addition of $3.2 \%$ essential amino acids (Table 3 ).

The observations on water quality revealed that the lowest average temperature was 27.5 to 28.7 o $\mathrm{C}$ in treatment $\mathrm{P} 1$, while the highest temperature was $27.6-28.60 \mathrm{C}$ in the treatment $\mathrm{P} 0$. The $\mathrm{P} 1$ treatment had the highest dissolved oxygen (DO) (4.81-6.92 mg/l), while the P0 treatment had the lowest DO (4.47-6.98 mg/l). The pH (7) and ammonia were the same in all treatment. Water quality is related to the metabolism and physiological processes in the absorption of feed, which were reported in the present study. 
Table 1. Average saturated fatty acid content of Pangasius fish (42 day-old) in Airlangga fish farm.

\begin{tabular}{lcc}
\hline Treatment & SFA $(\%)+$ SD & SFA \pm SD Transformation \\
\hline P0 $(0 \%)$ & $4.9668^{\mathrm{ab}} \pm 1.4542$ & $2.3205 \pm 0.3203$ \\
P1 $(1.2 \%)$ & $5.6868^{\mathrm{a}} \pm 1.2616$ & $2.4763 \pm 0.2618$ \\
P2 $(2.2 \%)$ & $5.4032^{\mathrm{a}} \pm 0.6675$ & $2.4266 \pm 0.1358$ \\
P3 $(3.2 \%)$ & $3.5882^{\mathrm{b}} \pm 0.9282$ & $2.0110 \pm 0.2371$ \\
\hline
\end{tabular}

Different superscripts in the same column indicate differences $(\mathrm{p}<0.05)$. SFA: Saturated Fatty Acid content, SD: Standard Deviation

Table 2. Average content of monounsaturated fatty acids of Pangasius Fish (42 day-old) in Airlangga fish farm.

\begin{tabular}{lcc}
\hline Treatment & MUFA (\%) + SD & MUFA Transformation \pm SD \\
\hline P0 $(0 \%)$ & $7.2466^{\mathrm{a}} \pm 1.1659$ & $2.7774 \pm 0.2014$ \\
P1 $(1.2 \%)$ & $5.7120^{\mathrm{b}} \pm 0.3942$ & $2.4914 \pm 0.0780$ \\
P2 $(2.2 \%)$ & $5.9630^{\mathrm{b}} \pm 0.7992$ & $2.5384 \pm 0.1557$ \\
P3 $(3.2 \%)$ & $5.5686^{\mathrm{b}} \pm 0.8716$ & $2.4581 \pm 0.1818$ \\
\hline
\end{tabular}

*Different superscripts in the same column show differences of ( $\mathrm{p}<0.05)$. SD: Standard Deviation, MUFA: Monounsaturated Fatty Acids

Table 3. Average content of monounsaturated fatty acid of Pangasius Fish (42 day-old) in Airlangga fish farm.

\begin{tabular}{llc}
\hline Treatment & MUFA (\%) + SD & MUFA Transformation \pm SD \\
\hline P0 $(0 \%)$ & $15.7392^{\mathrm{b}} \pm 4.2449$ & $4.0003 \pm 0.5439$ \\
P1 $(1.2 \%)$ & $15.2388^{\mathrm{b}} \pm 1.5001$ & $3.9634 \pm 0.1937$ \\
P2 $(2.2 \%)$ & $15.8804^{\mathrm{b}} \pm 1.1152$ & $4.0454 \pm 0.1386$ \\
P3 $(3.2 \%)$ & $23.1082^{\mathrm{a}} \pm 3.4405$ & $4.8483 \pm 0.3570$ \\
\hline
\end{tabular}

*Different superscripts in the same column show differences $(\mathrm{p}<0.01)$. SD: Standard Deviation, MUFA: Monounsaturated Fatty Acids

Table 4. Average results of water quality observation in Airlangga fish farm for rearing of Pangasius Fish.

\begin{tabular}{lcccc}
\hline Treatment & Temperature $\left({ }^{\mathbf{0}} \mathbf{C}\right)$ & Dissolved oxygen $\mathbf{~ m g} / \mathbf{L}$ & $\mathbf{p H}$ & Ammonia mg/l \\
\hline P0 & $27.6-28.6$ & $4.47-6.98$ & 7 & 0.003 \\
P1 & $27.4-28.7$ & $4.81-6.92$ & 7 & 0.003 \\
P2 & $27.5-28.6$ & $4.67-7.02$ & 7 & 0.003 \\
P3 & $27.5-28.7$ & $4.74-7.08$ & 7 & 0.003 \\
\hline
\end{tabular}

The current research indicated positive results in which the saturated fatty acids content was reduced when the commercial feed was mixed with lysine at 3.2\% $\left(\mathrm{P}_{3}\right)$, with the amount of lysine added being $2.1 \%\left(\mathrm{P}_{2}\right)$ and $1.2 \%\left(\mathrm{P}_{1}\right)$, respectively, the treatments indicated higher results than the control treatment $\left(\mathrm{P}_{0}\right)$. It is believed that the metabolic process and feed absorption in Pangasius species causing the supplemented amino acids in the commercial feed to be effective in reducing the saturated fatty acid content of pangasius meat. Treatment P1 and P2 revealed no decrease because the dose of the addition of lysine was in low level, and the absorption process in the body of pangasius was not optimal, suggesting that the addition of lysine did not decrease the SFA content of pangasius meat (Prananingtyas and Rahardja, 2019).

The data in table 1 indicated that the SFA content was $24.70 \%$. While in the present study, the total percentage of saturated fatty acids was $4.9112 \%$. The measurement of SFA was done using Analysis of Variants (ANOVA) and was obtained from two SFAs found in pangasius meat. It can be seen that the SFAs of pangasius have decreased due to the addition of the lysine in commercial feed. The lowest SFA content in the pangasius meat was $3.5882 \%$ found in the P3 treatment, while the highest UFA content was 5.5686\% found in the P1 treatment (Tables 1 and 2; Pamula, 2019).

The different results could be seen by good feed intake in each treatment significantly. The efficient use of the feed indicated the value of the percentage of feed that could be utilized by the body of the fish (Glencross et al., 2007). Saturated fatty acids have only a single bond on their hydrocarbon chains. In the meat of pangasius, the most SFAs were palmitic, stearic, and myristic acids. Palmitic acid is the highest saturated fatty acid (16.74\%). Pentadecanoic acid was the highest SFA in foods, accounting for $15-50 \%$ of all the fatty acids present (Putri and Dewi, 2019).

Based on the statistical calculations in table 3, adding lysine to the commercial feed caused a significant difference in the SFA content in the present study ( $\mathrm{p}<0.05$ ). The myristic fatty acid content was $4.9668 \%$ for P0, 5.6868\% for P1, $5.4032 \%$ for $\mathrm{P} 2$, and $3.5882 \%$ for $\mathrm{P} 3$, whereas the pentadecanoic acid average value was $4.5576 \%$ for $\mathrm{P} 0,4.9804 \%$ for $\mathrm{P} 1,4.559 \%$ for $\mathrm{P} 2$, and $3.0978 \%$ for $\mathrm{P} 3$.

The main effect of SFA was an increase in total cholesterol and LDL levels (LDL cholesterol) (Prananingtyas and Rahardja, 2019). The average intake of unsaturated fat to lower LDL cholesterol levels was $10 \%$ of total energy. 
Excessive consumption of saturated fat could cause the liver to produce large amounts of LDL cholesterol and increase blood cholesterol levels, which could later lead to thrombosis (Sonawane et al., 2017).

The content of MUFA in pangasius in the current study was quite high, with a size of $6-8 \mathrm{~cm}$ and a weight of 7-10 grams/head with a total amount of $6.1226 \%$ MUFA. In present experiment, the addition of lysine was proposed for increasing the MUFA level.

The present research indicated an increase in the total UFA level with the addition of lysine $\left(1.2 \% \mathrm{P}_{1}, 2.2 \% \mathrm{P}_{2}\right.$, and $3.2 \% \mathrm{P} 3)$ to the commercial feed, which indicated lower results than the control treatment $\left(\mathrm{P}_{0}\right)$. This is presumably due to the pangasius metabolism in treatment $\mathrm{P}_{1}, \mathrm{P} 2$, and $\mathrm{P} 3$, which differed from the pangasius metabolism in $\mathrm{P}_{0}$. Thus, the addition of the lysine indicated no increase in the MUFA content of pangasius meat. According to Pamula (2019), the content of fatty acids in the body depended on the ability of the fish break down essential fatty acids both naturally, both anabolically and catabolically (Pamula, 2019).

Monounsaturated fatty acid test results revealed that there are four types of fatty acids, such as palmitoleic acid, elaidic acid, and eicosenoic acid. Monounsaturated fatty acids have one carbon- carbon double bond in its carbon chain. These fatty acids are usually olefinic compounds with configuration cis and the double bonds are usually in certain positions. The most common type of MUFA group is $\omega-9$ with the position of a double bond on the 9 th carbon atom of the carboxyl group (Djoussé et al., 2012).

The results of the statistical analysis indicated a very significant difference $(\mathrm{p}<0.01)$ with each treatment. The PUFA level in pangasius meat increased due to the addition of the amino acid lysine in commercial feed. The highest PUFA level was found with the P3 treatment (23.1082\%), while the lowest was in the P0 treatment (15.7392\%).

$\beta$-oxidation is a process of synthesizing UFAs. Unsaturated fatty acids are more prone to oxidation and are easily exposed to foreign substances. However, $\beta$-oxidation could be prevented, because the metabolic process of UFA with the double bonds will be released at the stage of dehydrogenase II process. The process of dehydrogenase II would continue until the double bond is broken down into the acetyl-coA molecule.

The results of observations revealed that the good water temperature for pangasius is between $27.4^{\circ} \mathrm{C}$ and $28.7^{\circ} \mathrm{C}$ (Table 4). Drastic changes in temperature could kill the fish due to the changes in their blood carrying capacity. Temperature also affected the appetite of fish. Pangasius' appetite increased relatively in the morning and evening when the water temperature was between $27^{\circ} \mathrm{C}$ and $28^{\circ} \mathrm{C}$. The increase in temperature in the medium is influenced by the rate of metabolism (Fernandes et al., 2014). The temperature, as a physical quality of water, could affect fish activities, such as breathing, growth and reproduction. One of the water parameters that is very important for fish growth and survival was temperature. Temperature has a powerful impact on fish as fish are ectothermic, which means that fish could not produce body heat, thus their body temperature is dependent on the surrounding environment (Fitriani et al., 2019).

\section{CONCLUSION}

The use of amino acid lysine in commercial feed indicated significant differences in the saturated fatty acids, MUFA and PUFA levels in pangasius. The addition of lysine in commercial feed needs further investigation in the context of pangasius growth and reproduction cycle in order to increase pangasius productivity.

\section{DECLERATION}

\section{Author's contribution}

W. Nopita, M. Lamid, and Agustono had continuous and similar attempts in conduction and collection of samples and data, writing manuscript, and analysis of data. Authors approved the final version of the manuscript.

\section{Competing interests}

The author did not report any conflicts of interest in the current research.

\section{REFERENCES}

Adi P and Nugroh IMN (2020). Depiction of connection between library and information science in articles published by universitas airlangga's academics. International Journal of Innovation, Creativity and Change, 12: 963-976. Available at: https://www.ijicc.net/images/vol12/iss12/121292_Nugroho_2020_E_R.pdf

Bayati Zadeh J, Moradi kor Z, and Moradi kor N (2017). Synchronization of energy and protein on supply synthesis microbial protein. International Journal of Advanced Biological and Biomedical Research, 5(4): 174-177. Available at: http://www.ijabbr.com/article_33969.html

Bell RC, Zahradka P, Aliani M, Liang Y, McCargar LJ, Chan C, Ozga J, Proctor S, Wishart D, and Taylor C (2017). Dried beans lower cholesterol and glycated hemoglobin while peas lower blood pressure in adults with mild hypercholesterolemia. Federation of American Societies for Experimental Biology Journal, 31: 913-966. DOI: https://www.doi.org/10.1096/fasebj.31.1_supplement.966.13 
Djoussé L, Akinkuolie AO, Wu JHY, Ding EL, and Gaziano JM (2012). Fish consumption, omega-3 fatty acids and risk of heart failure: a meta-analysis. Clinical Nutrition, 31: 846-853. DOI: https://www.dx.doi.org/10.1016\%2Fj.clnu.2012.05.010

Fernandes CE, da Silva Vasconcelos MA, De Almeida Ribeiro M, Sarubbo LA, Andrade SAC, and de Melo Filho AB (2014). Nutritional and lipid profiles in marine fish species from Brazil. Food Chemistry, 160: 67-71. DOI: https://www.doi.org/10.1016/j.foodchem.2014.03.055

Fitriani EN, Arief M, and Suprapto H (2019). Prevalence and intensity of ectoparasites in gabus fish (Channa striata) at cangkringan fishery cultivation technology development center, Sleman, Yogyakarta, in: IOP Conference Series: Earth and Environmental Science. IOP Publishing, p. 12095. Available at: https://www.iopscience.iop.org/article/10.1088/1755-1315/236/1/012095

Glencross B, Booth M, and Allan G (2007). A feed is only as good as its ingredients - a review of ingredient evaluation strategies for aquaculture feeds. Aquaculture Nutrition, 13: 17-34. DOI: https://www.doi.org/10.1111/j.1365-2095.2007.00450.x

Jana A, Saroch JD, and Borana K (2014). Effect of Spirulina as a feed supplement on survival and growth of Pangasius sutchi. International Journal of Fisheries and Aquatic Studies, 1: 77-79. Available at: http://www.fisheriesjournal.com/archives/2014/vol1 issue5/PartB/98.pdf

Kim NK, Zealous Gietbong F, Andriyono S, Kim AR, and Kim HW (2018). The complete mitogenome of Bagrid catfish Chrysichthys nigrodigitatus (Siluriformes: Claroteidae). Mitochondrial DNA Part B, 3: 1239-1240. DOI: https://www.doi.org/10.1080/23802359.2018.1532341

Laake I, Carlsen MH, Pedersen JI, Weiderpass E, Selmer R, Kirkhus B, Thune I, and Veierød MB (2013). Intake of trans fatty acids from partially hydrogenated vegetable and fish oils and ruminant fat in relation to cancer risk. International Journal of Cancer, 132: 1389-1403. DOI: https://www.doi.org/10.1002/ijc.27737

Liu XY, Wang Y, and Ji WX (2011). Growth, feed utilization and body composition of Asian catfish (Pangasius hypophthalmus) fed at different dietary protein and lipid levels. Aquaculture Nutrition, 17: 578-584. DOI: https://www.doi.org/10.1111/j.13652095.2011.00859.x

Mahmud A, Girmatsion M, and Abraha B (2020). Fatty acid and amino acid profiles and digestible indispensable amino acid score of grass carp (Ctenopharyngodon idella) protein concentrate supplemented noodles. Journal of Food Measurement and Characterization, 14: 2370-2379. DOI: https://www.doi.org/10.1007/s11694-020-00484-3

Pamula OYT (2019). Optimization on survival and growth rate of African catfish (Clarias sp.) using water spinach (Ipomoea aquatica)-based aquaponics system. Aquarium, Conservation and Legislation, 12: 716-723. Available at: https://www.ec.europa.eu/research/participants/documents/downloadPublic/WjZnY0hKTTdFM3YyT1gyblRldlc1QVF0MzFYNGNGdHZRVER SL3BqL3BpV3o5bEVhak1FN2FnPT0=/attachment/VFEyQTQ4M3ptUWNDRDc2cnlEcVhQRjdlbWdyeEQ4MXI

Prananingtyas D, and Rahardja S (2019). Effect of different salinity level within water against growth rate, survival rate (FCR) of catfish (Clarias sp.), in: IOP Conference Series: Earth and Environmental Science. IOP Publishing, P. 12035. Available at: https://www.iopscience.iop.org/article/10.1088/1755-1315/236/1/012035/pdf

Putri FP, and Dewi NN (2019). Growth monitoring of koi fish (Cypri nus carpio) in natural hatchery techniques in Umbulan, Pasuruan, East Java, in: IOP Conference Series: Earth and Environmental Science. IOP Publishing, p. 12016. DOI: https://www.iopscience.iop.org/article/10.1088/1755-1315/236/1/012016/pdf

Sokoła-Wysoczańska E, Wysoczański T, Wagner J, Czyż K, Bodkowski R, Lochyński S, and Patkowska-Sokoła B (2018). Polyunsaturated Fatty Acids and Their Potential Therapeutic Role in Cardiovascular System Disorders-A Review. Nutrients, 10: 1561. DOI: https://www.doi.org/10.3390/nu10101561

Sonawane PD, Pollier J, Panda S, Szymanski J, Massalha Yona M, Unger T, Malitsky S, Arendt P, and Pauwels L (2017). Corrigendum: Plant cholesterol biosynthetic pathway overlaps with phytosterol metabolism. Nature Plants, 3: 17101. DOI: https://www.doi.org/10.1038/nplants.2017.101

Van Doan H, Doolgindachbaporn S, and Suksri A (2014). Effects of low molecular weight agar and Lactobacillus plantarum on growth performance, immunity, and disease resistance of basa fish (Pangasius bocourti, Sauvage 1880). Fish Shellfish Immunology, 41: 340-345. DOI: https://www.doi.org/10.1016/j.fsi.2014.09.015

Weya JM, Rumbiak NS, Hariyanto S, Irawan B, and Soegianto A (2017). Length-weight relationship and condition factor of crayfish from South Sorong and Jayawijaya, Papua, Indonesia. Croatian Journal of Fisheries, 75: 18-24. DOI: https://www.doi.org/10.1515/cjf-2017-0004

Yoo G, and Lee J (2016). The effect of feeding frequency, water temperature, and stocking density on the growth of river puffer Takifugu obscurus reared in a zero-exchange water system. Fisheries and Aquatic Sciences, 19: 23. DOI: https://www.doi.org/10.1186/s41240-016-0024-x 